\title{
Selection and evaluation of the efficiency of cutting inserts made of various cutting tool materials
}

\author{
Evgeniy Alekseevich Kudryashov \\ D.Sc. (Engineering), Professor \\ Scientific Research Engineering Institute \\ Balashikha, Moscow region, Russia \\ kea-swsu@mail.ru
}

\author{
Igor Mikhailovich Smirnov \\ D.Sc. (Engineering), Professor \\ Scientific Research Engineering Institute \\ Balashikha, Moscow region, Russia \\ pochta@aoniii.ru
}

\author{
Nikolay Andreevich Khizhnyak \\ Postgraduate student \\ Scientific Research Engineering Institute \\ Balashikha, Moscow region, Russia \\ kraxmalll@yandex.ru
}

\begin{abstract}
In Russia, in the last decade, practical steps for rise of machine-building production are taken. The key role belongs to metal working, development of progressive methods of production of details of machines of high constructive and technological complexity. The most effective is the way of intensification due to the expansion of tools' use equipped with artificial superhard materials on the basis of cubic boron nitride modifications. The results of scientific research of scientists and practicians emphasize the benefits of cutting methods of handling with modern tool materials before using the technologies of grinding. The use of machining technologies of structurally difficult details with tools, made from a composite 10, meets the requirements of the developers of the knowledge-intensive competitive equipment, tending to further increase in constructive complexity. Enhancement of machining processing of the details having structural elements of broken surface on the processed planes, with creation of special conditions of cutting by a method of management of the cutting part position, excluding a negative impact of dynamic loads on the tool is an urgent scientific and practical task.
\end{abstract}

Keywords-cutting tool, composites, intermittent turning, surface finish, efficiency

\section{INTRODUCTION}

It is known that an overwhelming quantity of details of machine-building production have various openings, grooves, bores and other structural elements on the processed surfaces, which form intermittence of cutting and negatively influence the firmness of cutting tools owing to strikes on the cutting edges. Therefore the choice of a rational brand, from the extensive list of tool materials, can be made only in the presence of exhaustive information on its physico-mechanical properties and features of application. The experience of domestic and foreign metal working emphasizes the benefits of artificial superhard materials on the basis of cubic boron nitride [1-5].
The short history of creation and development shows that for the first time cubic boron nitride was got in the USA in 1957, in 1959 it was synthesized in the USSR at the Institute of Physics of High Pressures named after L.F. Vereshchagin of the Academy of Sciences of the USSR. The industrial technology of getting this superhard material was firstly developed in LPO "The Abrasive Plant "Ilyich" and, since 1965 , the cutting tool, equipped with superhard materials had begun to be produced in lots by an industrial method.

The significant role in creation of new brands of tool materials and the cutting tools on their basis belongs to the Institute of superhard materials named after V. M. Bakul of NAN of Ukraine, scientific research institute of tool, etc.

The emergence of new tool materials attracts fixed interest as from the scientists, and production workers. Nearly in the seventies the scientific publications "Diamonds and Superhard Materials", "Synthetic Diamonds", "Metal-cutting and Control and Measuring Tool" have become a peculiar school on studying and experience generalization of the researches and industrial application of artificial superhard materials.

\section{THEORY}

In mechanical engineering technology, in metal working, the new scientific direction, connected with the development of tools' designs from artificial superhard materials and studying the methods of handling the details by them from various construction materials is created.

The initial stage is characterized by the emergence of various brands of superhard materials on the basis of cubic boron nitride: elbor-R, belbor, ismit, geksanit-R, etc., see in Fig. 1.

A variety of brands was explained by the fact that none of the cutting material the high durability and technological effectiveness were not combined with necessary cutting data, 


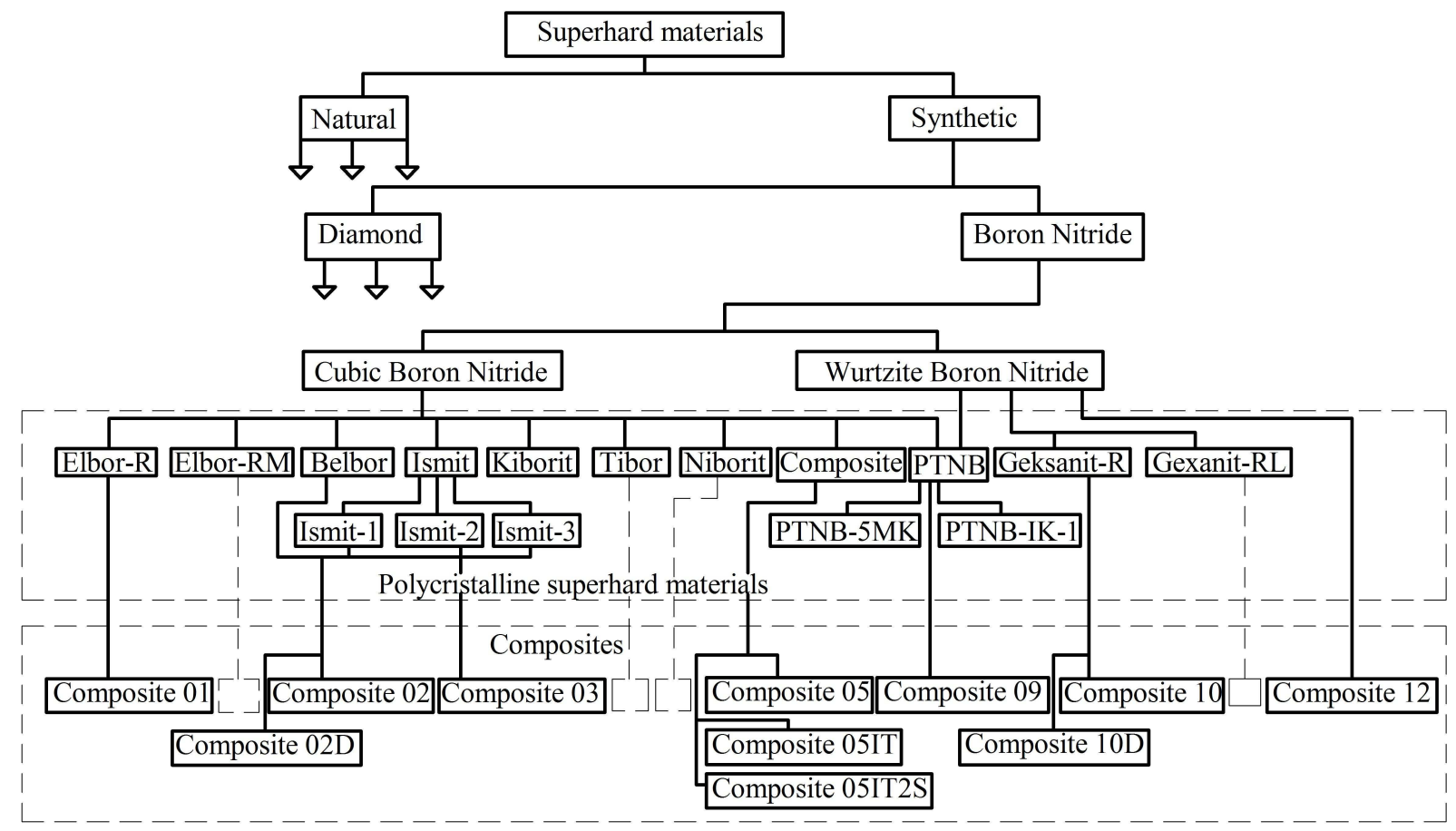

Fig.1. Classification of cutting materials on the basis of boron nitride

especially the cutting speed, and heat resistance, for the achievement of accuracy and quality indicators, corresponding to finishing processing. The tendency to creation of the best brand of cutting material, in the absence of the uniform regulatory base, has resulted in many inaccuracies and contradictions both in scientific research, and in practical activities.

As a necessary measure, VNIIinstrument has made a classification of the brands of artificial superhard materials which are available in industrial production with assignment of the composites' name, and also the list of requirements, imposed to the quality of cutting material, determined by a complex of physico-mechanical parameters. The list included the following physico-mechanical characteristics of artificial superhard materials: flexural strength, tensile strength, crossbreaking strength, density, elastic modulus, Poisson's ratio, thermal conductivity, thermal capacity, resistance to heating on air, microhardness, crack resistance coefficient, etc., see in Tab. 1.

The choice of a rational brand of cutting tool material is based on a reasonable compromise between its physicomechanical properties and the requirements for the conditions for turning surfaces of a complex profile. For example, high hardness tools are more prone to breakage; however, a decrease in hardness contributes to cracking conditions.

Based on the known information in the field of practical application of modern cutting tool materials, a set of requirements is formulated for the basic properties of a rational brand that is capable of resisting the negative factors of interrupted cutting without chipping and breaking the the cutting element:

- The hardness of the cutting tool material should be more than 2.5 times greater than the hardness of the

TABLE I. PHYSICO-MECHANICAL CHARACTERISTICS OF CUTTING MATERIALS

\begin{tabular}{|c|c|c|c|c|c|c|c|c|c|c|c|}
\hline & \multirow{3}{*}{$\begin{array}{l}\text { Physico-mechanical } \\
\text { characteristics }\end{array}$} & \multicolumn{10}{|c|}{ Brand of cutting material } \\
\hline & & \multicolumn{6}{|c|}{ Composites } & \multicolumn{2}{|c|}{ Cemented Carbides } & \multirow{2}{*}{$\begin{array}{c}\text { Ceramics } \\
\text { TsM332 }\end{array}$} & \multirow{2}{*}{$\begin{array}{l}\text { PTNB } \\
\text { Kiborit } \\
\end{array}$} \\
\hline & & 01 & 02 & 03 & 05 & 09 & 10 & $T 15 K 6$ & VK8 & & \\
\hline 1. & Compressive strength, $\sigma c, G P a$ & $\begin{array}{l}1.47- \\
3.15\end{array}$ & $\begin{array}{l}0.36- \\
0.38\end{array}$ & & $\begin{array}{l}0.96- \\
0.98\end{array}$ & $\begin{array}{l}0.98- \\
3.90\end{array}$ & $\begin{array}{l}1.96- \\
4.00\end{array}$ & $\begin{array}{l}3.82- \\
4.50\end{array}$ & $3.92-4.50$ & $0.88-1.47$ & $2.60-3.20$ \\
\hline 2. & Tensile strength, $\sigma t, G P a$ & $\begin{array}{l}0.70- \\
0.98\end{array}$ & $\begin{array}{l}0.68- \\
0.70\end{array}$ & & $\begin{array}{l}0.48- \\
0.49\end{array}$ & $\begin{array}{l}0.48- \\
1.19 \\
\end{array}$ & $\begin{array}{l}0.70- \\
1.50 \\
\end{array}$ & $\begin{array}{l}1.10- \\
1.15\end{array}$ & $1.55-1.60$ & $0.30-0.64$ & $0.55-0.65$ \\
\hline 3. & Density, $\rho, \mathrm{kg} / \mathrm{m}^{3}$ & $\begin{array}{l}3.31- \\
3.50\end{array}$ & $\begin{array}{l}3.42- \\
3.50\end{array}$ & $\begin{array}{l}3.30- \\
3.45 \\
\end{array}$ & $\begin{array}{l}3.17- \\
3.30\end{array}$ & $\begin{array}{l}3.59- \\
3.60\end{array}$ & $\begin{array}{l}3.28- \\
3.62\end{array}$ & $\begin{array}{l}11.0- \\
11.7\end{array}$ & $\begin{array}{l}8.00- \\
15.00\end{array}$ & $3.50-4.60$ & $3.20-3.34$ \\
\hline 4. & Elastic modulus, E, GPa & $\begin{array}{l}680- \\
840 \\
\end{array}$ & 720 & 720 & $\begin{array}{l}620- \\
700 \\
\end{array}$ & 500 & $\begin{array}{l}650- \\
780\end{array}$ & 55 & 59 & & $850-910$ \\
\hline 5. & Hardness, GPa & $32-38$ & $36-38$ & & 18.8 & & $30-38$ & $12.5-18$ & $11-17$ & $12-21$ & $32-36$ \\
\hline 6. & Thermal conductivity, $W /(m \times K)$ & $30-80$ & 80 & & & $60-70$ & $60-80$ & 27.21 & $58-58.7$ & 4.2 & 100 \\
\hline 7. & Resistance to heating on air, ${ }^{\circ} \mathrm{C}$ & $\begin{array}{l}1200- \\
1473 \\
\end{array}$ & $\begin{array}{l}900- \\
1323 \\
\end{array}$ & $\begin{array}{l}1000- \\
1200\end{array}$ & $\begin{array}{l}1000- \\
1100\end{array}$ & $\begin{array}{l}1000- \\
1100\end{array}$ & $\begin{array}{l}1000- \\
1500\end{array}$ & $\begin{array}{l}600- \\
1070\end{array}$ & $700-1170$ & $1200-1500$ & $1200-1573$ \\
\hline
\end{tabular}


workpiece material being machined, but not exceed the limits of their optimum ratio providing an acceptable ratio of hardness and strength of the cutting tool material.

- The cutting tool material must have sufficient mechanical tensile and flexural strengths and have high fracture toughness under cyclic loading.

- The cutting tool material must retain strength and wear resistance at high temperatures, be insensitive to cyclic changes in intermittent cutting temperature.

- The cutting tool material must have a good ability to rapidly remove heat from the cutting zone.

- The crystallochemical properties of the cutting tool material and the workpiece material must be significantly different, since their affinity strongly affects the adhesion and oxidation processes, the wear of the cutting element and the surface finish.;

- The cutting tool material should eliminate the difficulty of preparing the cutting element for sharpening before turning.

In Tab. 2 there are quantitative requirements for the physico-mechanical and chemical characteristics required for a rational brand of tool material, below which, in connection with the breaking of the cutting element, the use of the tool becomes impractical.

Comparison of physico-mechanical and chemical characteristics of cutting tool materials confirms the advantages of composites, and in particular of composite 10, which exceeds the level of required values of controlled characteristics related to the rational brand of cutting tool material (see in Tab. 2) and has better physico-mechanical characteristics among the most common brands of superhard materials used for intermittent cutting, Fig. 2.

The distinctive features of composites are not only the highest hardness. They are characterized by high wear resistance, low coefficient of friction, thermal conductivity, chemical resistance, reliability, durability and a great tool life. A particular advantage of composites over all brands of cutting tool materials is the chemical inert to ferrous metals (steel and their alloys, cast iron).

On the other hand, composites can be used for machining of non-ferrous alloys, as well as combinations of materials (ferrous and non-ferrous) in one combined surface, carbon and fiberglass.

The choice of the best brand of a composite can be performed also in a calculated way, by means of the coefficient, characterizing a numerical ratio of hardness of cutting material with a hardness of the workpiece material:

$$
K=\text { Hvim } / \text { Hvom }
$$

where Hvim - the hardness of cutting material, GPa, Hvom - the hardness of workpiece material, GPa.
The more the result of a ratio is, the higher the efficiency from the application of brand of a composite will be. From several brands of a composite, the preference has the one which value $K$ is the greatest.

\section{CONCLUSIONS}

The advantages of mechanical and physical characteristics of composites before other cutting materials allow to increase the productivity of various methods of metal working, including: turning details of different constructive complexity, turning powder coatings and weldup surfaces, face milling, threading, boring and reaming [6-10].

The analysis of literature and experience of practical activities in the field of design and improvement of technology of mechanical processing of details of the increased constructive complexity, allow drawing the following conclusions:

1) composites are the best cutting materials for intermittent cutting, they combine properties of high thermal stability and mechanical viscosity at destruction, and also chemical inertness in relation to the workpiece material;

2) the analysis of mechanical, physical and chemical characteristics of composites has allowed to establish minimum admissible values for them below which the practical sense of use of this group of cutting materials disappears;

3) a numerical indicator for the choice of the best brand of a composite is the coefficient, characterizing ratios of hardness of the instrumental and workpiece materials; the more the result of a ratio, the is higher efficiency from the applied composite brand is;

4) a number of the problems, demanding further development, is established:

a) it is difficult to compare and generalize the results of scientific search as there is no uniform technique of researches and conditions of experiments significantly differ;

$b)$ practically there are no conditions of selection and description of the sequence of actions for the choice of a set of the cutting tool and preparation it to work, etc.

TABLE II. LEVEL OF THE MINIMUM VALUES OF THE MECHANICAL, PHYSICAL AND CHEMICAL CHARACTERISTICS, SHOWN TO RATIONAL BRAND OF A COMPOSITE

\begin{tabular}{|l|l|}
\cline { 2 - 3 } \multicolumn{1}{c|}{} & \multicolumn{2}{c|}{ List of characteristics } \\
\hline 1. & Tensile strength, $\sigma \mathrm{c}>0.3 \mathrm{GPa}$ \\
\hline 2. & Flexural strength, $\sigma \mathrm{t}>0.6 \mathrm{GPa}$ \\
\hline 3. & Elastic modulus, $\mathrm{E} \approx 800 \mathrm{GPa}$ \\
\hline 4. & Fracture toughness, $\mathrm{K}_{\mathrm{IC}}>7 \mathrm{MPa} \times \mathrm{m} 1 / 2$ \\
\hline 5. & Coefficient of thermal conductivity, $\lambda>50 \mathrm{~W} / \mathrm{m} \times \mathrm{K}$ \\
\hline 6. & Resistance to heating on air $>1200^{\circ} \mathrm{C}$ \\
\hline 7. & Chemical inertness to workpiece material \\
\hline
\end{tabular}




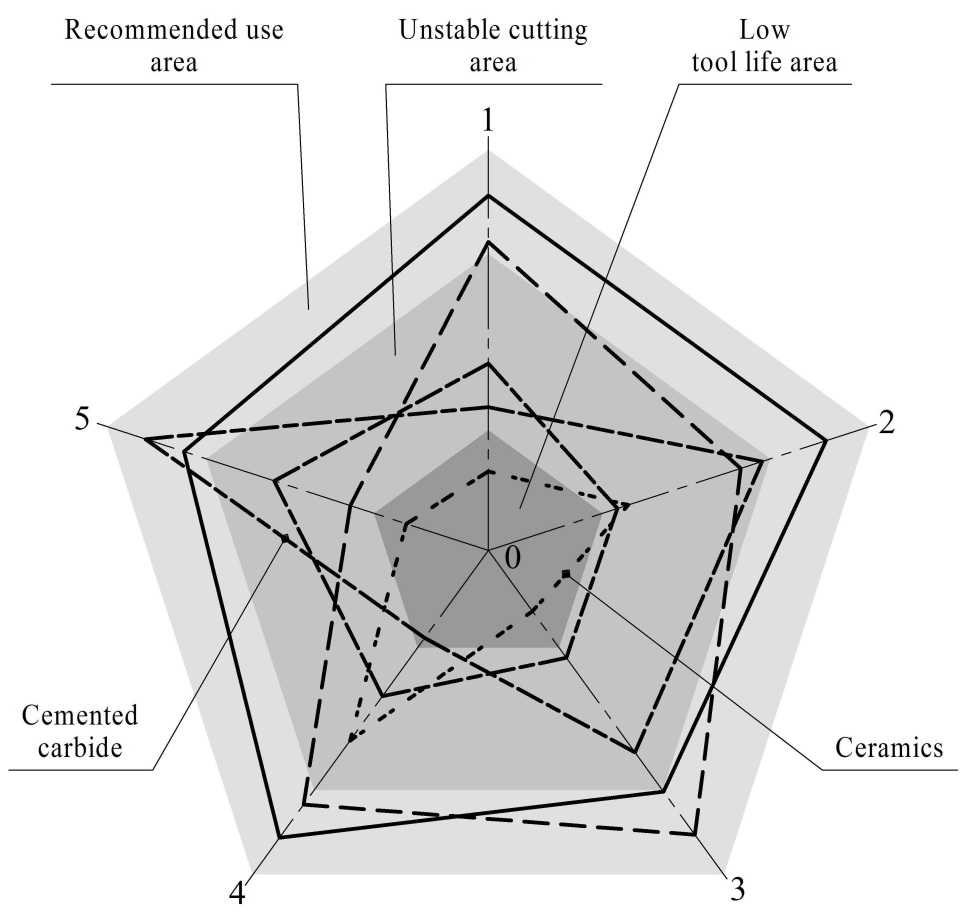

Physico-mechanical and chemical characteristics of cuting tool materials

\begin{tabular}{|c|c|c|c|c|c|c|}
\hline \multirow{2}{*}{\multicolumn{2}{|c|}{$\begin{array}{l}\text { Symbols of } \\
\text { composites }\end{array}$}} & 1 & 2 & 3 & 4 & 5 \\
\hline & & $\begin{array}{l}\text { Elastic } \\
\text { modulus }\end{array}$ & $\begin{array}{l}\text { Ultimate } \\
\text { flexural } \\
\text { strenght }\end{array}$ & $\begin{array}{c}\text { Ultimate } \\
\text { tensile strenght }\end{array}$ & $\begin{array}{l}\text { Termal } \\
\text { resistance }\end{array}$ & $\begin{array}{l}\text { Fracture } \\
\text { toughness }\end{array}$ \\
\hline & & $E, \mathrm{GPa}$ & $\sigma, \mathrm{GPa}$ & $\sigma, \mathrm{GPa}$ & $T,{ }^{\circ} \mathrm{C}$ & $K_{I C}, \mathrm{MPa} \times \mathrm{m}^{1 / 2}$ \\
\hline $\mathrm{C} 01$ & --- & 840 & 0.98 & 0.49 & 1470 & 4.17 \\
\hline $\mathrm{C} 05$ & -- & 700 & 0.50 & 0.22 & 1050 & 7.00 \\
\hline $\mathrm{C} 10$ & 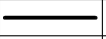 & 880 & 1.50 & 0.39 & 1500 & 7.12 \\
\hline Т15K6 & -- & 500 & 1.10 & 0.36 & 900 & 8 \\
\hline VOK-6 & $--\cdots$ & 350 & 0.60 & & 1200 & 3.10 \\
\hline
\end{tabular}

Fig.2. Comprasion of physico-mechanical and chemical characteristics

TABLE III. RATIO OF HARDNESS TOOL AND WORKPIECE MATERIALS

\begin{tabular}{|l|c|c|c|}
\hline \multirow{3}{*}{$\begin{array}{c}\text { Material of a } \\
\text { tool }\end{array}$} & \multicolumn{3}{|c|}{ Workpiece material } \\
\cline { 2 - 4 } & $\begin{array}{c}\text { PP-Np- } \\
\text { 25H5FMS }\end{array}$ & $\begin{array}{c}\text { PP-Np- } \\
\text { 35V9H3SF }\end{array}$ & $\begin{array}{c}\text { LS- } \\
\text { Coefficient } \boldsymbol{K} \text { - }\end{array}$ \\
\cline { 2 - 4 } & \multicolumn{3}{|c|}{ ComS } \\
\hline VK8 & 7.3 & 6.6 & 5.6 \\
\hline T15K6 & 7.9 & 7.7 & 6.1 \\
\hline VOK60 & 14.7 & 12.7 & 10.7 \\
\hline Composite 10 & 21.2 & 21.2 & 21.2 \\
\hline Kiborit & 36.5 & 36.5 & 36.5 \\
\hline
\end{tabular}

\section{References}

[1] Y. Sahin, Comparison of tool life between ceramic and cubic boron nitride $(\mathrm{CBN})$ cutting tools when machining hardened steels. Journal of materials processing technology, 2009, Vol. 209, № 7, pp. 3478-3489.

[2] J.E. Stahl, Metal cutting - Theories and models. Lund, Lund University, 2012.

[3] Y. Altintas, Manufacturing automation: metal cutting mechanics, machine tool vibrations, and $\mathrm{CNC}$ design. New York, Cambrdige University Press, 2012.
[4] D. Carou, E.M. Rubio, J.P. Davim, "Discontinuous cutting: failure mechanisms, tool materials and temperature study - a review," Reviews on Advanced Materials Science, 2014, Vol. 38, no. 2, pp. 110-124.

[5] E. A. Kudryashov, A. M. Nikonov, V. S. Rogovskii, A. V. Stetsurin, "Using superhard tools in discontinuous cutting," Russian Engineering Research, Vol. 29, No. 2, 2009, pp. 210-213.

[6] E. A. Kudryashov, I.M. Smirnov, "Tool guarantee of intermittent cutting processes," Manufacturing Technology, Vol. 17, No. 6, 2017, pp. 887892.

[7] P. De Vos, Applied metal cutting physics - Best practice. Fagersta, SECO Tools AB, 2016.

[8] W. Yulin, L. Tao, Q. Guo, H. Feng. Study on the forming process of thread raceway surface under the hard whirling. The 8th International Conference on Computer Science \& Education (ICCSE), 2013, pp. 627632.

[9] S.A. Klimenko, A.S. Manokhin, Yu.A. Mel'niichuk, "Wear and life of tools with inserts from cBN-based polycrystalline Superhard materials in the finish turning of hardened steels at heavy feeds," Journal of Superhard Materials, Vol. 31, No. 1, pp. 49-55.

[10] V. M. Bushlya, O. A. Gutnichenko, J. M. Zhou, J. E. Stahl, S. Gunnarsson, "Tool wear and tool life of PCBN, binderless $\mathrm{cBN}$ and wBN-cBN tools in continuous finish hard turning of cold work tool steel," Journal of Superhard Materials, 2014, Vol. 36, No. 1, pp. 49-60. 